\title{
Does Weight Loss improve Fertility with respect to Semen Parameters-Results from a Large Cohort Study
}

\author{
${ }^{1}$ Mir Jaffar, ${ }^{2}$ Mohammed Ashraf
}

\section{ABSTRACT}

Objective: To determine whether weight loss in obese men improves seminal parameters.

Design: Prospective interventional study.

Setting: Infertility clinic and weight loss centers.

Patient: All men attending infertility center and weight loss programmes from April 2012 to May 2015 ( $n=105)$.

Intervention: Diet counseling and exercise.

Main Outcome Measure: Collected reproductive parameters included semen analysis (ejaculate volume, sperm concentration, progressive and non-progressive motility) data. Body mass index (BMI) was calculated for all patients with comparisons to reproductive parameters before and after weight loss by using paired-t test and Chi-square tests.

Result: The mean BMI was significantly higher before weight loss (33.2) than after weight loss (30.4) in obese men. The weight loss had significant positive correlation with percentage of progressive sperm motility $(p=<0.001)$ and static percentage $(p=<0.001)$. Weight loss had non-significant correlation with semen volume $(p=0.083)$, concentration $(p=0.418)$ and non progressive motile sperm $(p=0.361)$.

Conclusion: In one of the largest cohorts of male fertility and obesity, semen parameters demonstrated mild but significant relationships with $\mathrm{BMI}$ and semen parameters, possibly contributing to subfertility in this population.

Keywords: Body mass index, Male infertility, Obesity, Semen analysis, Weight loss.

How to cite this article: Jaffar M, Ashraf M. Does Weight Loss improve Fertility with respect to Semen Parameters-Results from a Large Cohort Study. Int J Infertil Fetal Med 2017;8(1): 12-17.

Source of support: Nil

Conflict of interest: None

Date of received: $18-8-2016$

Date of acceptance: $30-9-2016$

Date of publication: May 2017

\footnotetext{
${ }^{1}$ Senior Research Scholar, ${ }^{2}$ Research Scholar

1,2Department of Embryology, Milann-The Fertility Center Bengaluru, Karnataka, India
}

Corresponding Author: Mir Jaffar, Senior Embryologist and Research Scholar, Department of Embryology, Milann-The Fertility Center, Bengaluru, Karnataka, India, Phone: +919886702931 e-mail: mir.jaffar@gmail.com

\section{INTRODUCTION}

According to the World Health Organization (WHO), infertility is "a disease of the reproductive system defined by the failure to achieve a clinical pregnancy after 12 months or more of regular unprotected sexual intercourse." Most of the developed countries are bearing the brunt of high frequency of overweight or obesity. ${ }^{1}$ In the developing world, the prevalence of overweight and obesity is increasing at alarming rates, ${ }^{2-6}$ and in some countries it has reached levels observed in the developed world. ${ }^{7,8}$ Although overweight and obesity have been demonstrated to affect female fertility, ${ }^{9}$ there is no consensus on the effects on male fertility and seminal parameters. ${ }^{10-12}$ Recent epidemiological studies conducted on male infertile couples suggest that obesity is associated with decline in male fertility. ${ }^{13}$ Male obesity has been linked to subfecundity and an effect-response relationship between increasing body mass index (BMI) and subfecundity has been proposed. ${ }^{14-16}$ Urbanization is one of the main reasons for higher prevalence of obesity in developing countries in terms of food intake and physical activity. Apart from poor lifestyle, genetic makeup also plays a role in increasing obesity in India. India and most of the Asia-Pacific population have mutation of MC4R genes, which puts them into high-risk population. ${ }^{17}$ The WHO has reclassified the obesity limits for Asians/Indians as indicated in Table $1 .^{18}$

It is well documented that there is a strong association between obesity and poor semen parameters, ${ }^{19-26}$ although with conflicting results. ${ }^{11,27-32}$ Obesity has shown to affect the gonadotropin-releasing hormone-luteinizing hormone/follicle-stimulating hormone (GnRH-LH/FSH) pulse that may impair Leydig and Sertoli cell functions and with the release of sex hormones with consequent effect on sperm maturation. ${ }^{33}$ It is demonstrated that

Table 1: The WHO-recommended classification for Indian population

\begin{tabular}{lcc}
\hline \multicolumn{3}{c}{ Body mass index cut-off values for adults } \\
\hline \multicolumn{2}{c}{ Asians/Indians 2000 } \\
\hline Underweight & $<18.5$ & $<18.5$ \\
Normal range & $18.5-24.9$ & $18.5-22.9$ \\
Overweight (preobese) & $25.0-29.9$ & $23.0-24.9$ \\
Obese class I & $30.0-34.9$ & $25.0-29.9$ \\
Obese class II & $35.0-39.9$ & $\geq 30.0$ \\
Obese class III & $\geq 40.0$ &
\end{tabular}

$1 \mathrm{WHO}^{8} /$ Technical Report Series (TRS 894)

$2 \mathrm{WHO} /$ The International Obesity Task Force (IOTF)/International Association for the Study of Obesity (IASO) ${ }^{18}$ 
altered hormonal profile in obese men have negative impact on semen parameters.

Decreased levels of gonadotropins, free testosterone, sex hormone-binding globulin and also increased levels of estrogens are mainly associated with obesity-related infertility. ${ }^{34-37}$ All these alterations might affect the male reproductive system and gamete quality. Previous studies have shown that the endocrine abnormalities may be reversed by weight reduction. ${ }^{38-43}$ Our study aimed to find the changes in different semen parameters before and after weight loss program in obese men.

\section{MATERIALS AND METHODS}

Obese men aged 25 to 40 years (mean age $=32.5 \pm 7.5$ ) with BMI more than $25 \mathrm{~kg} / \mathrm{m}^{2}$ were recruited for the study. All the participants were subjected to weight loss intervention and followed up for 1 year after weight loss.

We excluded two men diagnosed with Klinefelter's syndrome, and in the analyses of semen characteristics, two with retractile testis and seven men with azoospermia were excluded because azoospermia probably is not caused by obesity alone. The weight loss program was based on healthy diet and exercise that lasted for approximately 3 months. All the participants were asked to fill up the questionnaires related to their reproductive activities, medical and surgical history, and their lifestyle before and after weight loss intervention.

Prader orchidometer was used to measure the volume of each testis. The clinical examination was performed on site by one investigator and included blood pressure by mercurial sphygmomanometer, blood sugar level (Accucheck), and height and weight measurements (Table 2).

A sterile nontoxic container was provided to the participants to collect the semen sample by masturbation. They were instructed to maintain at least 48 hours of abstinence. Participants were given the option of semen collection at home on their request. A written consent was taken from the participants and no incentives were given for the participation. The study was approved by our regional ethics committee with the approval number as P-RM-08/2012.

Table 2: Characteristics of study participants

\begin{tabular}{|c|c|c|c|}
\hline Parameter & $\begin{array}{l}\text { Before } \\
\text { intervention }\end{array}$ & $\begin{array}{l}\text { After } \\
\text { intervention }\end{array}$ & $\%$ change \\
\hline $\mathrm{BMI}<18.5\left(\mathrm{~kg} / \mathrm{m}^{2}\right)$ & $0(0 \%)$ & $0(0 \%)$ & $0.0 \%$ \\
\hline BMI 18.5-24.9 (kg/m²) & $0(0 \%)$ & $11(10.5 \%)$ & $10.5 \%$ \\
\hline BMI 25.0-29.9 $\left(\mathrm{kg} / \mathrm{m}^{2}\right)$ & $25(23.8 \%)$ & $47(44.8 \%)$ & $21.0 \%$ \\
\hline BMI 30.0-34.9 (kg/m²) & $57(54.3 \%)$ & $31(29.5 \%)$ & $-24.8 \%$ \\
\hline BMI 35.0-39.9 (kg/m²) & $12(11.4 \%)$ & $7(6.7 \%)$ & $-4.7 \%$ \\
\hline $\mathrm{BMI} \geq 40.0\left(\mathrm{~kg} / \mathrm{m}^{2}\right)$ & $11(10.5 \%)$ & $9(8.6 \%)$ & $-1.9 \%$ \\
\hline Smoking & $34(32.4 \%)$ & $34(32.4 \%)$ & $0.0 \%$ \\
\hline Alcohol consumption & $21(20 \%)$ & $14(13.3 \%)$ & $-6.7 \%$ \\
\hline Hypertension & $10(9.5 \%)$ & $11(10.5 \%)$ & $1.0 \%$ \\
\hline Diabetes & $7(6.7 \%)$ & $7(6.7 \%)$ & $0.0 \%$ \\
\hline
\end{tabular}

BMI: Body mass index

\section{ANALYSES OF SEMEN SAMPLES}

Semen volume was estimated by $3 \mathrm{~mL}$ Pasteur pipette (Tarsons). Sperm concentration and motility were assessed as described in "WHO Laboratory Manual". 8 Semen sample analysis was performed within 1 hour after ejaculation, since sperm motility is stable within this time. ${ }^{44}$ CASA system (CASA, Nikon, Model Eclipse E200) was used for count and motility. Mackler chamber was also used to countercheck the concentration.

Men diagnosed with azoospermia or severe oligospermia $\left(<5 \times 10^{6}\right)$ were ruled out for Y-chromosome microdeletions. Then they were subjected to weight reduction program, which includes diet counseling, exercise, and / or lipolysis for a duration of minimum 3 months. All the previous tests were repeated once again and the results were compared with their previous results and the difference studied.

\section{Statistical Methods}

Descriptive and inferential statistical analysis has been carried out in the present study. ${ }^{45-48}$ Continuous variables were presented as mean \pm standard deviation. Categorical variables were presented as percentages and number of events. We used paired-t test and Chi-square tests to compare the means and evaluate their associations. Data were collected on Microsoft Excel on a standardized sheet. Analysis was performed using Statistical Package for the Social Sciences version 12.0. P-value of $<0.05$ was regarded as significant.

\section{RESULTS}

Data were prospectively collected between April 2012 and May 2015. A total of 213 men were invited to participate of which 126 men (57\%) were recruited. Out of the 126 participants, 21 were excluded according to our exclusion criteria (16\%), and remaining 105 were actually recruited for our weight loss program.

The data of the studied groups are represented in Table 3. The mean BMI was significantly higher in group I (before weight loss) than in group II (after weight loss) obese men. We observed that weight loss improved the percentage of sperm motility, while the percentage of static sperm decreased. Weight loss had nonsignificant correlation with sperm concentration, nonprogressive sperm percentage, and a suggestive significant correlation with semen volume (Table 3 and Graphs 1A to F).

Study design: Prospective interventional study

\section{DISCUSSION}

Studies are limited regarding the impact of weight loss with diet and exercise on male fertility. Most of the 
Table 3: Assessment of study variables before and after intervention

\begin{tabular}{lllccc}
\hline Variables & Before intervention & After intervention & Difference & $t$-value & $p$-value \\
\hline Body mass index $\left(\mathrm{kg} / \mathrm{m}^{2}\right)$ & $33.18 \pm 5.06$ & $30.43 \pm 5.98$ & 2.755 & 10.257 & $<0.001^{\text {** }}$ \\
Vol in $\mathrm{mL}$ & $2.44 \pm 0.80$ & $2.52 \pm 0.67$ & -0.085 & -1.751 & $0.083^{\dagger}$ \\
Count/mL & $36.38 \pm 27.05$ & $37.43 \pm 23.46$ & -1.051 & -0.814 & 0.418 \\
Progressive \% (PR) & $29.35 \pm 21.91$ & $41.06 \pm 24.40$ & -11.712 & -4.282 & $<0.001^{\text {** }}$ \\
Non-progressive \% (NR) & $17.57 \pm 9.71$ & $18.70 \pm 9.49$ & -1.130 & -0.917 & 0.361 \\
Static \% & $53.70 \pm 24.27$ & $39.97 \pm 22.50$ & 13.737 & 5.386 & $<0.001^{\text {** }}$ \\
\hline
\end{tabular}

Student's t test (paired); ${ }^{\dagger}$ suggestive significance $(0.05<p<0.10)$; moderately significant $(0.01<p \leq 0.05) ;{ }^{* *}$ strongly significant $(p \leq 0.01)$
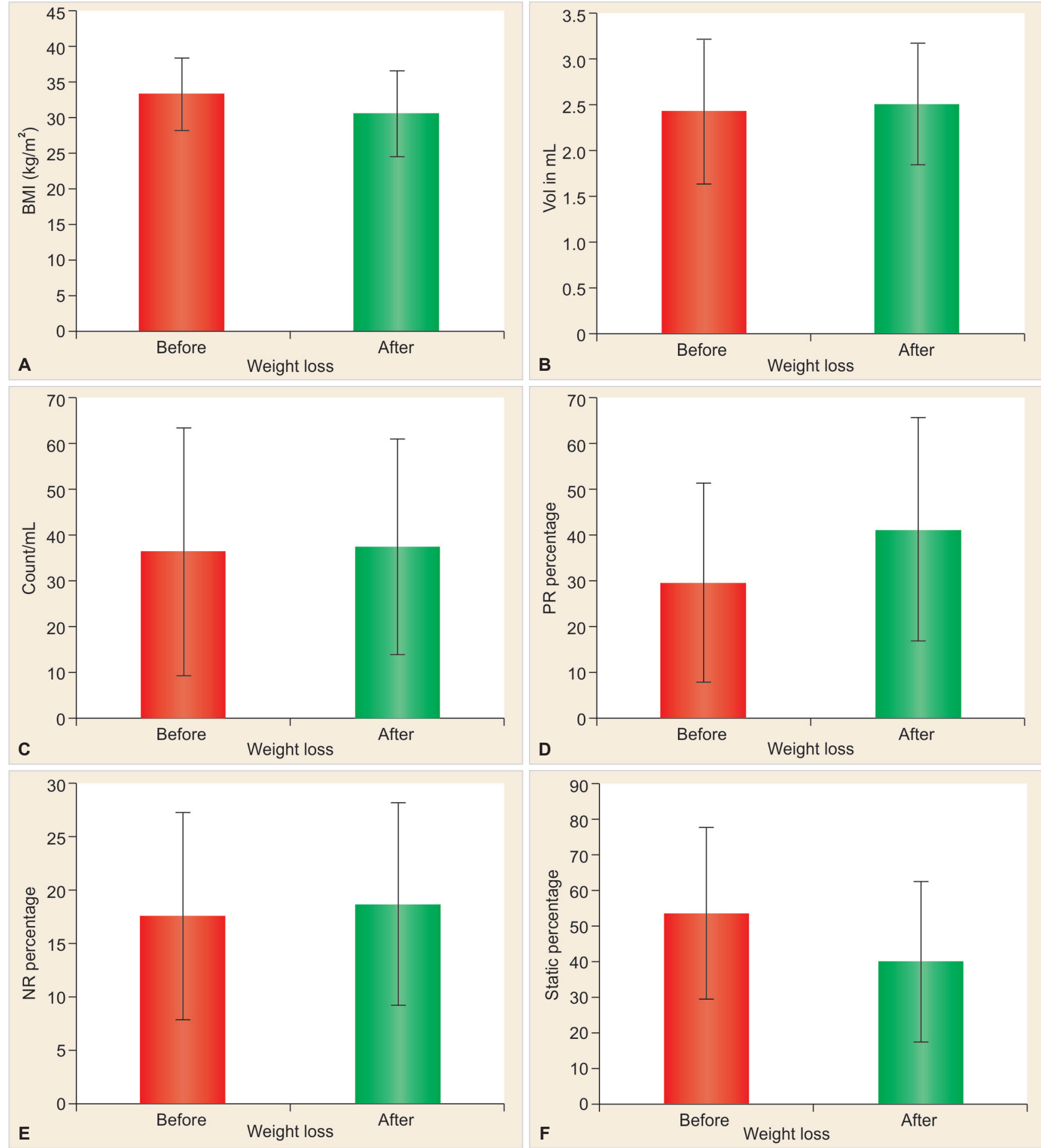

Graphs 1A to F: Impact of weight loss on different seminal parameters 
available studies are conducted in clinical setup, where the participants tend to be infertile. This study evaluates the effects of obesity and weight loss interventions in male fertility in the general population.

Our study showed that a high BMI was associated with low values of sperm concentration, total sperm count, and percentage of motile sperm.

We did not observe statistically significant differences in sperm concentration, volume, or nonprogressive sperm count. Weight loss was associated with an increase in the percentage of progressive motile sperm and decrease in static sperm percentage among men who participated in a 12-week weight loss program. Our results indicate that there is a causal inverse association between BMI and semen quality, suggesting that it may be possible to improve semen quality by weight reduction. Previous studies have reported a higher prevalence of oligospermia in overweight and obese men than in normal weight men, with a significant association between sperm count and BMI. ${ }^{19}$

A study conducted on normal weight and obese men, both having normal semen parameters, reported lower sperm count in obese group compared with the normal group. ${ }^{49}$ It is well established that obesity also has a negative impact on the morphology of sperm. ${ }^{23}$

Obesity has been implicated to have direct and indirect impacts that could reduce male fertility including decreased sperm motility and increased DNA fragmentation. ${ }^{14,16}$ Obese men suffering from sleep apnea have shown improved testosterone levels after weight loss. ${ }^{50}$ There is a strong correlation between physical activity and erectile function. Physical activity has been shown to improve sexual activities, especially among males who were less active earlier. ${ }^{51}$ Obese men with metabolic syndrome also have shown improvement in erection function after reducing caloric intake.

Improvement in sexual activity is also reported after weight loss by gastric bypass surgical means..$^{52}$ Even though natural weight loss and gastric bypass have shown promising results in terms of restoring fertility and surgical treatment has been shown to restore reproductive hormones to normal levels, some studies indicate that gastric bypass procedure and the drastic weight loss might induce secondary infertility. According to a report, six morbidly fertile obese men lost 60 to $80 \mathrm{~kg}$ after a Roux-en-Y gastric bypass developed secondary infertility and complete azoospermia and ultimately landed up with complete spermatogenic arrest. ${ }^{53}$ The BMI does not directly reflect the percentage of body fat, but is a measure of weight in relation to height. Some muscular men may have high BMI despite not being obese, which may not be associated with poor semen quality.

The BMI does not directly reflect the percentage of fat as such, but is a measure of weight in relation to height. Few men have high BMI because of large muscle mass, such men may not have compromised semen quality. Chances of influence on our findings by different confounders like smoking, alcohol, diabetes mellitus, hypertension, and abstinence time are obvious. We did, however, take into account these factors in the regression analyses and they are unlikely to explain our findings.

It should be noted that few men in spite of losing weight remained overweight/obese after the weight loss program.

\section{CONCLUSION}

To conclude on this study, we observed that the altered androgen profile tended to improve following weight loss and that weight loss may potentially lead to improvement in semen quality, although we cannot conclude this to be a result of the reduction in body weight per se.

A lot of research still needs to be carried out to clear the gray area to set up concrete mechanisms involved in obesity and develop an effective treatment protocol for obese infertile men. There is enough clinical evidence regarding obesity and its role in infertility, so there should be a different approach implemented toward preconception management in obese men. However, the available clinical evidence is strong enough for health policies to be implemented immediately in public and private settings regarding preconception counseling and different approach of treatment for obese population without further delay. The promotion of weight excess prevention and control, especially through lifestyle therapies, should be mandatory not only for improving reproductive and obstructive outcomes but also for reducing the cost of medical treatment eradicating or treating the secondary diseases with obesity as the root cause.

\section{REFERENCES}

1. Ogden CL, Carroll MD, Curtin LR, McDowell MA, Tabak CJ, Flegal KM. Prevalence of overweight and obesity in the United States, 1999-2004. JAMA 2006 Apr;295(13):1549-1555.

2. Tuan NT, Tuong PD, Popkin BM. Body mass index (BMI) dynamics in Vietnam. Eur J Clin Nutr 2008 Jan;62(1):78-86.

3. Dearth-Wesley T, Wang H, Popkin BM. Under- and overnutrition dynamics in Chinese children and adults (1991-2004). Eur J Clin Nutr 2008 Nov;62(11):1302-1307.

4. Uauy R, Albala C, Kain J. Obesity trends in Latin America: transiting from under- to overweight. J Nutr 2001 Mar;131(3): 893S-899S.

5. Villamor E, Msamanga G, Urassa W, Petraro P, Spiegelman D, Hunter DJ, Fawzi WW. Trends in obesity, underweight, and wasting among women attending prenatal clinics in urban Tanzania, 1995-2004. Am J Clin Nutr 2006 Jun;83(6):1387-1394.

6. Rivera JA, Barquera S, González-Cossío T, Olaiz G, Sepúlveda J. Nutrition transition in Mexico and in other Latin American countries. Nutr Rev 2004 Jul;62(7 Pt 2):S149-S157. 
7. Filozof C, Gonzalez C, Sereday M, Mazza C, Braguinsky J. Obesity prevalence and trends in Latin-American countries. Obes Rev 2001 May;2(2):99-106.

8. WHO Consultation on Obesity (1999: Geneva). Obesity: preventing and managing the global epidemic: report of a WHO consultation. Geneva: World Health Organization; 2000.

9. Fedorcsák P, Dale PO, Storeng R, Ertzeid G, Bjercke S, Oldereid N, Omland AK, Abyholm T, Tanbo T. Impact of overweight and underweight on assisted reproduction treatment. Hum Reprod 2004 Nov;19(11):2523-2528.

10. Strain GW,Zumoff B,KreamJ,StrainJJ, Deucher R, Rosenfeld RS, Levin J, Fukushima DK. Mild hypogonadotropic hypogonadism in obese men. Metabolism 1982 Sep;31(9):871-875.

11. Pauli EM, Legro RS, Demers LM, Kunselman AR, Dodson WC, Lee PA. Diminished paternity and gonadal function with increasing obesity in men. Fertil Steril 2008 Aug;90(2):346-351.

12. Hammoud AO, Wilde N, Gibson M, Parks A, Carrell DT, Meikle AW. Male obesity and alteration in sperm parameters. Fertil Steril 2008 Dec;90(6):2222-2225.

13. Hammoud AO, Gibson M, Peterson CM, MeikleAW, CarrellDT. Impact of male obesity on infertility: a critical review of the current literature. Fertil Steril 2008 Oct;90(4):897-904.

14. Sallmén M, Sandler DP, Hoppin JA, Blair A, Baird DD. Reduced fertility among overweight and obese men. Epidemiology 2006 Sep;17(5):520-523.

15. Ramlau Hansen $\mathrm{CH}$, Thulstrup AM, Nohr EA, Bonde JP, Sorensen TIA, Olsen J. Subfecundity in overweight and obese couples. Hum Reprod 2007 Jun;22(6):1634-1637.

16. Nguyen RH, Wilcox AJ, Skjaerven R, Baird DD. Men's body mass index and infertility. Hum Reprod 2007 Sep;22(9): 2488-2493.

17. Lee YS. Melanocortin 3 receptor gene and melanocortin 4 receptor gene mutations: the Asian perspective. Diabetes Metab Res Rev 2012 Dec;28 (Suppl 2):26-31.

18. WHO/IOTF/IASO. The Asia-Pacific perspective: redefining obesity and its treatment; 2000.

19. Jensen TK, Andersson AM, Jørgensen N, Andersen AG, Carlsen E, Petersen JH, Skakkebaek NE. Body mass index in relation to semen quality and reproductive hormones among 1,558 Danish men. Fertil Steril 2004 Oct;82(4):863-870.

20. Magnusdottir EV, Thorsteinsson T, Thorsteinsdottir S, Heimisdottir M, Olafsdottir K. Persistent organochlorines, sedentary occupation, obesity and human male subfertility. Hum Reprod 2005 Jan;20(1):208-215.

21. Koloszár S, Fejes I, Závaczki Z, Daru J, Szöllosi J, Pál A. Effect of body weight on sperm concentration in normozoospermic males. Arch Androl 2005 Jul-Aug;51(4):299-304.

22. Fejes I, Koloszár S, Závaczki Z, Daru J, Szöllösi J, Pál A. Effect of body weight on testosterone/estradiol ratio in oligozoospermic patients. Arch Androl 2006 Mar-Apr;52(2): 97-102.

23. Kort HI, Massey JB, Elsner CW, Mitchell-Leef D, Shapiro DB, Witt MA, Roudebush WE. Impact of body mass index values on sperm quantity and quality. J Androl 2006 May-Jun;27(3):450-452.

24. Stewart TM, Liu DY, Garrett C, Jorgensen N, Brown EH, Baker HW. Associations between andrological measures, hormones and semen quality in fertile Australian men: inverse relationship between obesity and sperm output. Hum Reprod 2009 Jul;24(7):1561-1568.

25. Chavarro JE, Toth TL, Wright DL, Meeker JD, Hauser R. Body mass index in relation to semen quality, sperm DNA integrity, and serum reproductive hormone levels among men attending an infertility clinic. Fertil Steril 2010 May;93(7):2222-2231.

26. Hofny ER,AliME,Abdel-HafezHZ,KamalEel-D,MohamedEE, Abd El-Azeem HG, Mostafa T. Semen parameters and hormonal profile in obese fertile and infertile males. Fertil Steril 2010 Jul;94(2):581-584.

27. Qin DD, Yuan W, Zhou WJ, Cui YQ, Wu JQ, Gao ES. Do reproductive hormones explain the association between body mass index and semen quality? Asian J Androl 2007 Nov;9(6): 827-834.

28. Aggerholm AS, Thulstrup AM, Toft G, Ramlau-Hansen $\mathrm{CH}$, Bonde JP. Is overweight a risk factor for reduced semen quality and altered serum sex hormone profile? Fertil Steril 2008 Sep;90(3):619-626.

29. Ramlau-Hansen $\mathrm{CH}$, Hansen $\mathrm{M}$, Jensen CR, Olsen J, Bonde JP, Thulstrup AM. Semen quality and reproductive hormones according to birthweight and body mass index in childhood and adult life: two decades of follow-up. Fertil Steril 2010 Jul;94(2):610-618.

30. Wise LA, Rothman KJ, Mikkelsen EM, Sørensen HT, Riis A, Hatch EE. An internet-based prospective study of body size and time-to-pregnancy. Hum Reprod 2010 Jan;25(1):253-264.

31. Martini AC, Tissera A, Estofán D, Molina RI, Mangeaud A, de Cuneo MF, Ruiz RD. Overweight and seminal quality: a study of 794 patients. Fertil Steril 2010 Oct;94(5):1739-1743.

32. MacDonald AA, Herbison GP, Showell M, Farquhar CM. The impact of body mass index on semen parameters and reproductive hormones in human males: a systematic review with meta-analysis. Hum Reprod Update 2010 May-Jun;16(3): 293-311.

33. Bélanger $\mathrm{C}$, Luu-The $\mathrm{V}$, Dupont $\mathrm{P}$, Tchernof A. Adipose tissue intracrinology: potential importance of local androgen/estrogen metabolism in the regulation of adiposity. Horm Metab Res 2002 Nov-Dec;34(11-12):737-745.

34. Kaufman JM, Vermeulen A. The decline of androgen levels in elderly men and its clinical and therapeutic implications. Endocr Rev 2005 Oct;26(6):833-836.

35. Isidori AM, Caprio M, Strollo F, Moretti C, Frajese G, Isidori A, Fabbri A. Leptin and androgens in male obesity: evidence for leptin contribution to reduced androgen levels. J Clin Endocrinol Metab 1999 Oct;84(10):3673-3680.

36. Aggerholm AS, Thulstrup AM, Toft $\mathrm{G}$, Ramlau-Hansen $\mathrm{CH}$, Bonde JP. Is overweight a risk factor for reduced semen quality and altered serum sex hormone profile? Fertil Steril 2008 Sep;90(3):619-626.

37. Qin DD, Yuan W, Zhou WJ, Cui YQ, Wu JQ, Gao ES. Do reproductive hormones explain the association between body mass index and semen quality? Asian J Androl 2007 Nov;9(6): 827-834.

38. Stanik S, Dornfeld LP, Maxwell MH, Viosca SP, Korenman SG. The effect of weight loss on reproductive hormones in obese men. J Clin Endocrinol Metab 1981 Oct;53(4):828-832.

39. Strain GW, Zumoff B, Miller LK, Rosner W, Levit C, Kalin M, Hershcopf RJ, Rosenfeld RS. Effect of massive weight loss on hypothalamic-pituitary-gonadal function in obese men. J Clin Endocrinol Metab 1988 May;66(5):1019-1023.

40. Pasquali R, Casimirri F, Melchionda N, Fabbri R, Capelli M, Platè L, Patrono D, Balestra V, Barbara L. Weight loss and sex steroid metabolism in massively obese man. J Endocrinol Invest 1988 Mar;11(3):205-210.

41. Bastounis EA, Karayiannakis AJ, Syrigos K, Zbar A, Makri GG, Alexiou D. Sex hormone changes in morbidly obese patients 
after vertical banded gastroplasty. Eur Surg Res 1998;30(1): 43-47.

42. Kaukua J, Pekkarinen T, Sane T, Mustajoki P. Sex hormones and sexual function in obese men losing weight. Obes Res 2003 Jun;11(6):689-694.

43. Niskanen L, Laaksonen DE, Punnonen K, Mustajoki P, Kaukua J, Rissanen A. Changes in sex hormone-binding globulin and testosterone during weight loss and weight maintenance in abdominally obese men with the metabolic syndrome. Diabetes Obes Metab 2004 May;6(3):208-215.

44. Makler A, Zaidise I, Brandes JM. Elimination of errors induced during a routine human sperm motility analysis. Arch Androl 1979 Nov;3(3):201-210.

45. Rosner, B. Fundamentals of biostatistics. 5th ed. Duxbury; Blackwell; 2000. p. 80-240.

46. Riffenburg, RH. Statistics in medicine. 2nd ed. San Diego: Academic Press; 2005. p. 85-125.

47. Sunder Rao, PSS.; Richard, J. An introduction to biostatistics. A manual for students in health sciences. 4th ed. New Delhi: Prentice Hall of India; 2006. p. 86-160.
48. Suresh K, Chandrashekhara S. Sample size estimation and power analysis for clinical research studies. J Hum Reprod Sci 2012 Jan;5(1):7-13.

49. Koloszár S, Daru J, Kereszturi A, Závaczki Z, Szöllosi J, Pál A. Effect of female body weight on efficiency of donor AI. Arch Androl 2002 Sep-Oct;48(5):323-327.

50. Semple PA, Graham A, Malcolm Y, Beastall GH, Watson WS. Hypoxia, depression of testosterone, and impotence in Pickwickian syndrome reversed by weight reduction. Br Med J (Clin Res Ed) 1984 Sep;289(6448):801-802.

51. Hannan JL, Maio MT, Komolova M, Adams MA. Beneficial impact of exercise and obesity interventions on erectile function and its risk factors. J Sex Med 2009 Mar;6 (Suppl 3):254-261.

52. Hammoud A, Gibson M, Hunt SC, Adams TD, Carrell DT, Kolotkin RL, Meikle AW. Effect of Roux-en-Y gastric bypass surgery on the sex steroids and quality of life in obese men. J Clin Endocrinol Metab 2009 Apr;94(4):1329-1332.

53. di Frega AS, Dale B, Di Matteo L, Wilding M. Secondary male factor infertility after Roux-en-Y gastric bypass for morbid obesity: case report. Hum Reprod 2005 Apr;20(4):997-998. 